\title{
Motivation and Foreign Language Learning: Exploring the Rise of Motivation Strategies in the EFL Classroom
}

Hamza Alshenqeeti*

Taibah University, Madinah, Saudi Arabia

Corresponding Author: Hamza Alshenqeeti, E-mail: hshenqeeti@taibahu.edu.sa

\section{ARTICLE INFO}

Article history

Received: May 31, 2018.

Accepted: August 20, 2018

Published: December 01, 2018

Volume: 7 Issue: 7

Advance access: October 2018

Special Issue on Language \&Literature

Conflicts of interest: None

Funding: None

\begin{abstract}
Students facing difficulties in learning English because of a range of factors and issues are often demotivated to learn. This has a direct impact on the entire learning process. Research into motivation in the EFL classroom has discovered that certain strategies can encourage learners to think more positively and thus be more motivated in their language learning process. This paper critically discusses types of motivation strategies in the EFL classroom and their increase in popularity. Following this, it critically considers ways in which motivation strategies are still lacking and hence presents some approaches to better promote these from the perspective of students, teachers and policy makers. Along with providing specific recommendations for further research on L2 motivation, the paper concludes by calling on for adopting a range of motivational strategies that can improve student foreign language learning.
\end{abstract}

Key words: EFL, Learning strategies, Motivation, Motivational frameworks, Motivation strategies

\section{INTRODUCTION}

Motivating students to learn another language is a multifaceted, and constantly changing, issue. Students facing difficulties in learning English as a foreign language (EFL) because of a range of factors and issues are often demotivated to learn. This has a direct effect on the learning process. Research into motivation in the EFL classroom has discovered that certain strategies can encourage learners to think more positively and thus be more motivated in their learning process. Saito, et al. (2017), for instance, claim that motivation is one of the most crucial topics in today's field of EFL as it concerns both how content is taught, and how students are learning. It also holds autonomous learning at its heart, something which has been quite popular in the past ten years. This is in line with Ushioda (2014, p.31) who states that motivation is "a variable of importance in human learning, reflected in goals and directions pursued, levels of effort invested, depth of engagement, and degree of persistence in learning". However, motivational strategies employed in the language classroom are still fairly dated and not relevant to a changing society (Hsu, 2017).

This paper explores motivation strategies in the EFL classroom and the ways in which they need to be developed. The paper is divided into three main sections. It begins by documenting motivation within an EFL context and its role and importance within a language learning context (Section 2). Section 3 then focuses on specific motivation strategies that are in use in EFL classrooms and contexts and the cur rent relevant literature surrounding them. These will be analysed and critically assessed. Finally, Section 4 will conclude by proposing ways in which motivation strategies are still lacking and approaches to better promote them from the standpoint of students, teachers and policy makers.

\section{MOTIVATION IN LANGUAGE LEARNING}

\section{Motivation and EFL}

Motivation is a crucial facet in the language learning process (Zhou, 2018; Gardner, et al., 2004; Spada \& Lightbown, 1993) and has been defined in many ways as it embodies a multitude of concepts. It is generally characterised as a learner's "willingness or desire to be engaged in or commit effort to completing a task" (Zhou, 2012, p.1318). Without the desire to learn, students are less likely to co-operate, take self-responsibility, or fully engage in the language learning process. As noted by Dörnyei (1998, p.117), motivation "energises" human behaviour and "gives it direction". This is in line with Wlodwoski (1985) who views motivation as "the processes that can (a) arouse and instigate behaviour, (b) give direction or purpose to behaviour, (c) continue to allow behaviour to persist, and (d) lead to choosing or preferring a particular behaviour" (p.2). This definition is close to that of Dörnyei and Otto (1998, p.65) who define motivation as "the dynamically changing cumulative arousal in a person that initiates, directs, coordinates, amplifies, terminates, and evaluates the cognitive and motor processes whereby initial 
wishes and desires are selected, prioritized, operationalized and (successfully or unsuccessfully) acted out". According to Dörnyei (2001, p.116), "teacher skills in motivating learners should be seen as central to teaching effectiveness". By this, teachers are viewed as the key holders and one of their roles is unlocking motivation in students. This is not an easy process as motivation depends on an extended array of factors both inside and outside of the individual learner. This places a great demand on teachers' capabilities (Oxford \& Amerstorfer, 2018). However, motivation is also described as a significant constituent of classroom learning which students are able to independently self-control. A certain amount of motivation must come from the learner as well as the learning environment. This means that both the teacher and the students are heavily invested in fostering motivation.

Critical discourse analysts, social psychologists and most EFL specialists acknowledge that the language teacher/student relationship is based on power. This power may be divided into three main types - coercive, reward-based, and referent, or motivational (Thanasoulas, 2002). This third type is claimed to be the most operative and practical power relationship given that it embraces a student-centred strategy, meaning that students' choices and actions play a direct role in their learning. A student with more motivation will take more responsibility for their learning and a student given more autonomy will subsequently have more motivation. Autonomy-promoted learning, then, is seen as a primary driving force in raising learner motivation and will be discussed in relation to a range of specific strategies in Section 3 of this paper.

Whilst it is evident that people can have varying degrees or strengths of motivation, there are also different kinds of motivation. These relate to the principal attitudes, beliefs and objectives which often instigate a form of action (MacIntyre \& Vincze, 2017). At its most basic level, motivation distinguishes two different branches: intrinsic and extrinsic. 'Intrinsic motivation' has come to be used to refer to doing a task because it is interesting to a person or that a person finds it enjoyable, whilst the term 'extrinsic motivation' has been applied to situations where students do something because they expect it to bring about an outcome, such as employment or profitmaking. Previous studies (e.g. Ryan \& Deci, 2000) have revealed that "the quality of experience and performance can be very different when one is behaving for intrinsic versus extrinsic reasons" (p.55).

Intrinsic motivation was first demonstrated experimentally on animal behaviour during the 1950s. Specifically, it has been shown that certain animals engage in curiosity-driven learning without the presence of a reward or reinforcement (White, 1959). These behaviours "although clearly bestowing adaptive benefits on the organism, appear not to be done for any such instrumental reason, but rather for the positive experiences associated with exercising and extending one's capacities" (Ryan \& Deci, 2000, p.56). Thus, while extrinsic motivation is defined as carrying out an action for a reward, intrinsically-motivated activities are undertaken for the reward of the activity itself. Humans are naturally inquisitive and curious, and they display readiness to learn and explore from birth. This is a crucial aspect of cognitive, physical and social development. In EFL, intrinsic motivation has been shown to lead to "high-quality learning and creativity" (Ryan \& Deci, 2000, p.55) and has emerged as a crucial factor which can be fostered or undermined by parents, teachers and policy makers (Ryan \& Stiller, 1991). If students have an inner drive to learn a language, they find satisfaction and drive in the learning process itself. Most of the day-to-day activities people undertake do not hold any intrinsic motivation. This is particularly the case in late childhood onwards, as freedom becomes increasingly impacted upon by social influence, demands and the desire to conform (Ryan \& Deci, 2000). In schools, the same researchers claim that intrinsic motivation weakens with each school year.

The literature surrounding extrinsic motivation is more controversial. Ryan and Deci (2000), amongst other researchers, argue that learners "can perform extrinsically-motivated actions with resentment, resistance, and disinterest or, alternatively, with an attitude of willingness that reflects an inner acceptance of the value or utility of a task" (p.55). An external motivational factor or goal may contrast with the inner beliefs or attitudes of the learning process itself. Extrinsic motivation can also vary in its level of autonomy. A student who does their homework only because they do not want to face the repercussions is extrinsically motivated because they are doing it to arrive at the outcome of averting consequences of not doing it. Similarly, a student who completes the homework because of his/her belief that it is useful for their future career is also extrinsically-motivated (on account of its influential merit, in lieu of its appeal). Both of these examples are described as instrumental, yet the latter involves a feeling of choice rather than compliance with an external force.

To develop this idea more clearly, types of extrinsic motivation can be divided into four main branches. These are: external regulation (doing something to satisfy the demands placed upon us); introjected regulation (when a person feels pressured into doing something); identification (identifying the personal importance to doing something); and integrated regulation. This last form involves self-examination and an integration with a person's other values and needs. According to Ryan and Deci, "the more one internalises the reasons for an action and assimilates them to the self, the more one's extrinsically motivated actions become self-determined" (2000, p.60). More integrated types of motivation overlap with intrinsic motivation, both being self-directed. They are still classed as extrinsic however, because integrated regulation means something is done for its contributory worth (i.e. an outcome that is unattached to behaviour). Most researchers believe that types of motivation can be placed along a cline with the most intrinsic and extrinsic positioned at each extreme (MacIntyre \& Vincze, 2017). Of course, motivation types can interplay, and one type can drive or develop another type, such as the pressure to get a good job, which may, in time, drive a more intrinsic motivation when one becomes pleased and confident as their abilities and competencies develop. Indeed, competence is one of many factors that impact on motivation strength and type. A large range of EFL theories explore the factors which influence student motivation in foreign language contexts. These are now discussed in the following subsection. 


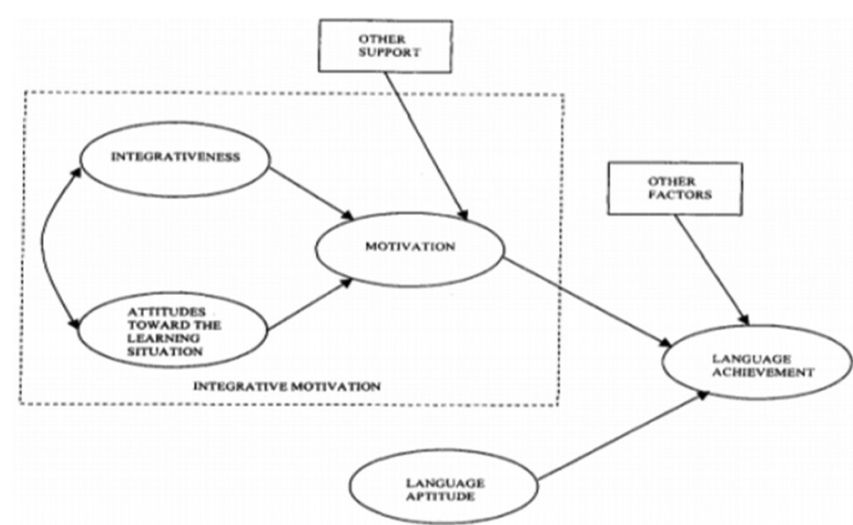

Figure 1. Gardner's Socio-educational Model (Gardner, 1983, p. 220)

\section{Motivating Language Learners}

Research into L2 learning motivation has largely been inspired by Clément (1980) and Gardner $(1983,1985)$ up until the 1990s. During this time, learner motivation was seen as heavily affected by their (learners', that is) attitudes towards the second language itself along with the social perceptions of that language's speakers (Dörnyei, 2001). Gardner (1985) also claimed that attitudes towards a particular language group will affect how successful a learner becomes in acquiring that language. Williams (1994) supported this view, arguing that when learning a language, we learn not merely the skills and/or system-based rules. Rather, language learning is embedded in our sense of identity and how we are able to express this identity through linguistic means. It includes "an alteration in self-image, the adoption of new social and cultural behaviours and ways of being and, therefore, has a significant impact on the social nature of the learner" (Bahous et al., 2011, p.34). Thus, motivation is not simply dependent on one's competencies and performance-based achievement, but on much less tangible factors such as the ideology one attaches to the language and their perception of oneself as a speaker of that language. This is explained in Gardner's Socio-educational Model. "A main feature of the socio-educational model is motivation" (Gardner, 2006, p. 242).

Subsequent research into L2 learner motivation by Dörnyei (1994, 1998, 2001) and Williams (1994) also focused on the urge for a more pragmatic-centred attitude. This meant examining the classroom environment and identifying specific learner motives for being a part of that environment. Dörnyei and Csizer (1998, p.215) cited ten factors for "motivating language learners" within the classroom environment. These commandments can be summarised as the following: teachers should set an example in terms of behaviour, promote a relaxed classroom environment, maintain sound teacher-student relationships, increase learners' self-esteem, make sure that language classes are thought-provoking, personalise the learning process for the learners, promote learner autonomy, present tasks clearly, increase learner goals, and promote the L2 culture. The study has since been replicated (for instance, Cheng \& Dörnyei, 2007) and culture and identity have been found to be two crucial variables in learner motivation.
However, this approach to motivation placed too much control and responsibility on the teacher. Since the rise in more student-led approaches to teaching, this framework has also had to adapt. Since the 1990s, researchers have extended their views on motivation in relation to L2 language learning and also acknowledged cognitive and environmental factors as well as social dimensions. Simard and Wong (2004), for example, state that this wider consideration of motivation also promotes greater cross-cultural understanding. Dörnyei (2010) describes this concept as L2 "motivational self-esteem", emphasising the link between language learning and one's 'core' set of values and beliefs or identity. The implication is that a learner develops emotional maturity and, consequently, self-motivation in L2 acquisition. Since the 1990s, Burden (2004) also promoted the idea of communicative learning and its link to motivation. According to him, learners need to realise that the purpose of L2 use is for effective communication, rather than for achieving academic success. Strengthening this claim, Dörneyi (1990) and Oxford (1996) have also found that when learners can measure the practical outcomes to the learning process, they are much more motivated.

Importantly, Gardner, et al. (2014) also demonstrate the importance of affective factors such as motivation on L2 acquisition and mastery. Specifically, they looked at the impact of language instruction on "language attitudes, motivation, and anxiety that take place over the academic year" (Gardner, et al., 2014, p.7). They drew upon the Attitude Motivation Test Battery (AMTB) in order to assess specific affective variables: a desire to learn French, the intensity of their own motivation, attitudes towards learning the language and towards language speakers (French Canadians), and general interest in other languages. Their findings revealed that students' attitudes are heavily persuaded by both the classroom environment and the teacher. Specifically, as the experiences varied in the different classes, so too did the students' interest in learning French and foreign languages more generally. Thus, we return to the position of the significant role of the teacher in the engagement process. The researchers suggested that specific teacher strategies should be introduced in the language classroom, in order to increase student motivation amongst other affective factors. Ideally, Thanasoulas (2002) claims that all learners will "exhibit a curiosity to explore the world", thus finding the learning experience intrinsic. However, this curiosity is often dampened by unavoidable factors such as compulsory school attendance, exams and grades and curriculum content. Whilst a degree of autonomy and student input in the learning process and curriculum design can minimise this, these factors are still inescapable. Unless teachers can increase "goal-orientedness". in learners, they will come up against a de-motivated class.

Good and Brophy (1994, p.212) acknowledge that approaches and strategies put in place to promote and encourage learner motivation in the EFL classroom have so far been influenced by two contradictory views. The first idea is that learning should be enjoyable for a learner and consequently that a lack of motivation is attributed to the teacher's lack of skill. Secondly is the idea that school activities are characteristically boring and/or unrewarding, and therefore teachers 
need to rely on extrinsic rewards and punishment. Instead, Ryan and Deci (2000) claim that knowing ways to best promote more active forms of extrinsic motivation should be a necessary strategy not only for individual teachers but at the level of policy planning and implementation also. Dörnyei (2001, p.119) believes that "the spectrum of other potentially more effective motivational strategies is so broad that it is hard to imagine that none of them would work". What follows is a discussion of motivational strategies and their success.

\section{MOTIVATION IN CONTEXT}

\section{Motivational Frameworks}

Thanasoulas (2002) proposed a useful framework for organising motivational strategies following a process-oriented model designed by Dörnyei and Otto (1998). It appears to be one of the most comprehensible frameworks found in the literature; they also claim that whilst there is a large body of literature on classroom-specific motives, these publications fall short of offering an effective practical guide to teachers. The framework they propose succeeds in doing this (they claim) and thus will be reviewed here. It can be divided into the following four categories (the phase in brackets corresponds to that of Dörnyei and Otto's similar model):

"1. Creating the basic motivational conditions, for the use of motivational strategies

2. Generating student motivation (the pre-actional phase)

3. Maintaining and protecting that motivation (the actional phase)

4. Encouraging positive self-evaluation (the postactional phase)" (Thanasoulas, 2002, p.4).

Motivational strategies do not operate in a vacuum. They also have to be flexibly sufficient for individual teachers to follow. As a necessary condition, the teacher must show appropriate behaviour and a good rapport with students. This, according to Dörnyei (2001, p.120), is "a powerful motivational tool". Alison (1993) adds that an important thing to do is to establish trust and respect with the learners. It is also important to have a supportive atmosphere; "a tense classroom climate can undermine learning and demotivate learners" (MacIntyre, 1999:24). Finally, there must be a cohesive learner group with common aims. There are many factors which can affect group cohesiveness, including the amount of time spent together, shared group history, interaction, common threats, group competition, and the presence of the leader (Ehrman \& Dörnyei, 1998). Once these necessary pre-conditions are met, motivational strategies can be implemented, and filter down through the stages 2-4.

According to the researcher's model, these strategies can be divided into: creating realistic learner beliefs, making the curriculum relevant, increasing learner's self-confidence, creating learner autonomy and increasing learner satisfaction. In relation to the first type of strategy, creating genuine learner beliefs, "it is widely acknowledged that learner beliefs about how much progress to expect, and at what pace, can, and do, lead to disappointment" (Thanaso- ulas, 2002, p.4). Learners need to get rid of preconceived notions about the learning process then, and instead, develop an understanding of second language learning. An important acknowledgement is that second language competence can be achieved in many ways, with a variety of strategies, and that learners must discover the optimal methods and approaches for themselves. Of course, this relies on a flexible teaching method.

The second type of strategy (making the curriculum relevant), depends again, on the teacher and even those above in policy planning. Thanasoulas $(2002$, p.4) claims that "in order to inspire learners to concern themselves with most learning activities, we should find out their goals and the topics they want to learn and try to incorporate them into the curriculum". This notion is supported by Chambers (1999): "If the teacher is to motivate pupils to learn, then relevance has to be the red thread permeating activities" (p.37). However, it is not necessarily as straight forward and where schools and classes are large, individual input into the curriculum or syllabus is difficult. There are also problems with making a student-centred curriculum coherent with a governmental policies and educational standards/targets. This is something which will be discussed again later.

The third strategy type is increasing learner's self-confidence. Dörnyei (2001) claims there are five approaches to do this and that in the face-threatening classroom environment, this is a crucial aspect of increasing and maintaining motivation. These are listed below (Dörnyei, 2001, p.130):

1. "Teachers can foster the belief that competence is a changeable aspect of development.

2. Favourable self-conceptions of L2 competence can be promoted by providing regular experiences of success.

3. Everyone is more interested in a task if they feel that they make a contribution.

4. A small personal word of encouragement is sufficient.

5. Teachers can reduce classroom anxiety by making the learning context less stressful".

One potential criticism of this framework is that the types of strategies are not interdependent and many of these ways to increase self-confidence remarked upon by Dörnyei (2001) are also a part of fulfilling the other strategies, for instance, promoting autonomy would also help to encourage self-confidence.

Learner autonomy and self-motivation go together. Ushioda (1997, p.41), states that "self-motivation is a question of thinking effectively and meaningfully about learning experience and learning goals. It is a question of applying positive thought patterns and belief structures so as to optimise and sustain one's involvement in learning". Autonomy is something that is argued for and promoted by many researchers, teachers and other educators (for example Bravo et al., 2017; Benson, 2000; Little, 1991). Taking charge of one's own learning has been proven to be beneficial to learning in a number of contexts and settings. Rogers (1961:276) claims that "the only kind of learning which significantly affects behaviour is self-discovered, self-appropriated learning". Benson (2000) is known for his work on autonomy and he distinguishes between five types of practice which nurture and foster learner autonomy. These 
are "resource-based, learner-based, classroom-based, technology-based and curriculum-based approaches" (Benson, 2000, p.112).

Finally, in this framework, comes satisfaction. According to Thanasoulas (2002, p.4) "satisfaction is a significant factor in reinforcing achievement behaviour". Current motivational strategies which aim at providing a sense of learner satisfaction often focus on techniques such as allowing students to display their work, celebrating academic achievements and using rewards. However, one problem with a rewards-based system is that it contrasts with a system where results are the ultimate example of reward. Grades are a sign of performance outcome rather than representative of the learning process. As a consequence, "many students are grade driven, not to say, 'grade grubbing', and this preoccupation begins surprisingly early in life" (Covington, 1999, p.127). The reward system is also problematic as it pushes motivation towards the extrinsic end of the motivational cline and focus is taken away from the more personal, intrinsic reasons for learning. This framework, drawing on Dörnyei (2001) highlights some crucial factors involved in nurturing motivation amongst students. As mentioned, some of the strategy types feed into one another, and it is also not an exhaustive list of strategies. Thanasoulas (2002) does make it clear that there is a wide variety of macro strategies also utilised to promote motivation. The research is also fairly dated today. However, it can be argued that his framework does not acknowledge what some researchers take as crucial factors which can hinder or promote autonomy within the EFL classroom. These will be discussed and reviewed for the remainder of this section.

\section{Acknowledging Learning Styles and Motivation}

One fundamental consideration when designing strategies for use in the classroom is that learners learn differently and are motivated by different things. With its belief that all people have different kinds of intelligences, Gardner's (1983) Theory of Multiple Intelligences can potentially be considered as an effective approach for understanding and identifying different abilities in learners. Previous learning experiences should also be taken into consideration when designing course content and strategies. In situations where all students are learning the same content, teachers can respond to the content with a range of written and spoken activities, for example. This gives students the opportunity to choose from several options, such as written reports, comparison and contrast papers and debates, for instance. Bravo, et al., (2017) and Fortini and Fizpatrick (2000) also suggest that curriculums are redesigned, however, unlike Thanasoulas (2002, p.2), they offer the idea of "adopting a universal design; creating and designing products and environments for particular purposes". Rose, et al. (2002) also support this approach claiming that it promotes engagement amongst learners. Shih and Reynolds (2018) defend the view that teaching strategies shall go beyond simply delivering instruction to including a type of content that is relevant for students. Udvari-Solner, et al. (2005) also claim that meaningful involvement for students must be taken into consideration when designing classes and content but so far there has been little research into communicative approaches and how they can support motivation and specifically communicative activities which promote motivation.

\section{On Technology and Motivation}

The use of technology in teaching languages has the potential to cultivate motivation in students as well as augmenting learning as a whole. Research into this aspect of language teaching is currently lacking, which is surprising in light of the popularity of technology in this area, which has been increasing in recent years. However, Al-Jarf (2014) studied the impact of technology when teaching writing to Saudi EFL learners. The findings of this study showed increased motivation amongst students at an implicit level. The research saw two groups of students being given a writing task centred on a textbook, with the experimental group stimulated to use the Internet and apps outside classes to develop their papers. Following a post-experiment test, it was demonstrated that the latter group not only achieved higher grades in their written test, but also enjoyed a greater sense of achievement and higher levels of self-esteem. Technology was therefore seen to have made writing a more agreeable task, as well as encouraging the exchange of ideas outside class and fostering a sense of autonomy.

Other studies have similar findings, including that of Ramachaudran (2004), who asserted that technology allows students to use their language of study in a more diverse manner, within a broader range of contexts. Students are empowered to decide on their own learning styles and activities as a degree of control is moved away from teachers. Another study by (Kim, 2003) found that students who used email in language tasks and "were interacting with other learners, teachers and online learning content became more expressive than when taking part in traditional classroom-based approaches" (p.4). Other studies, even more recently, have concluded the same and even introduced the use of smartphones to the classroom with positive benefits for motivation (Leis, et al., 2018).

\section{Employing a Reward System}

As was mentioned briefly in Thanasoulas' (2002) motivational framework, rewards are one strategy that can help encourage and motivate students extrinsically. In some EFL classroom environments, language teachers successfully use rewards in order to enhance motivation, despite the controversy involved in promoting extrinsic forms of motivation. Researchers such as Meyer (1995) call for the development and implementation of national programmes for student rewards in order to improve students' reading and other skills. Johnson, et al. (1995) call these programmes "Earning by Learning (EBL)". Students who are academically low achieving are rewarded with both cash and adult attention when they read. As the discussion has shown, intrinsic motivational strategies are still favoured by teachers, educators and those who have influence in policy decisions, yet some researchers are currently pushing for extrinsic rewards to 
motivate a certain strand of learners who are "academically frustrated". Oldfather (1995) sees it as a step towards creating a more intrinsic type of motivation; by providing rewards, students are brought back into the learning sphere with an encouragement or motivation that can potentially set them on a track towards inner satisfaction and self-esteem. Once such students reach a higher academic level, Oldfather (1995) argues that they will then be on a par with classmates and be driven towards fulfilling what become more personal goals. Terrell and Rundulic (1996) are also in favour of this approach and claim that rewarding students for doing a task helped improving self-esteem, as implied through the literature, increases their motivation. McNinch (1997) applied the same programme in the States and provided a cash prize for students. Volunteers worked with students who had academic struggles and the findings from this study showed an increase in self-esteem (84\%) and academic grades (72\%) as well as attitudes towards the school $(86 \%)$. The author concluded that along with the incentive, it was the provision of caring adults and rich reading material that improved reading motivation. While the results of such studies are encouraging, it is necessary that they are followed up to see whether and the extent to which they help improve students' achievement (Dörneyi, 2001).

Operant conditioning theory (Skinner, 1953) supports the reward-based system as it maintains that all behaviour is motivated by rewards (in other words by a separable consequence such as food or money). Some supporters of the theory even go as far as to claim that intrinsically motivated activities also depend on a reward, the reward being in the activity itself or the sense of achievement. On the contrary, learning theory (Hull, 1943) claims that learner behaviour is driven by physiological drives, and thus intrinsically-motivated tasks are those which provided satisfaction of intrinsic emotional needs. The argument lies in seeing self-esteem, confidence and sense of achievement as a psychological need rather than a separable consequence. However, while factors such as competency, autonomy, and relatedness can be seen as psychological, the fundamental need for satisfaction comes in part from engaging externally in interesting activities. Most researchers are still opposed to the reward system (regardless of actual teacher practices) and there is a current trend towards identifying the characteristics which make a task or activity interesting. Ryan and Deci (2002, p.57), for instance, urge that there is a "considerable practical utility in focusing on task properties and their potential intrinsic interest, as it leads towards improved task design or selection to enhance motivation". There is abundant room for further progress in investigating what needs are fulfilled by intrinsically-motivated behaviours is a particular topic that requires more attention in relation to this.

\section{CONCLUSIONS AND PROPOSALS FOR ENCOURAGING MORE COMMUNICATIVE MOTIVATION STRATEGIES}

In this paper, the aim was to assess the rise of motivation strategies in the EFL classroom. A major conclusion of this paper is that motivation in EFL contexts is faced with many challenges. If reforms are to be made they should start right from the beginning of students' educational journey. Many researchers reach the same conclusion that there should be a range of materials that cater for different learning styles are available for the students, and that this is a major factor in fostering and promoting motivation. Classes need to be student-centred and this can be managed through approaches such as collaborative learning and technology use, as has been shown. Stimulating positive student attitudes towards the target language is also a key factor which can be achieved through a variety of strategies.

Despite the rise in motivation literature and the current trend in promoting motivational strategies, there still remains a lack of research that focuses on comunicative teaching and how motivation can be achieved through communicative learning. Providing learners "with opportunities to interact freely and learn from each other's mistakes" (Spada \& Lightbown, 1993, p.26), appears to be the only research study in this specific field but more focus is needed on making classrooms and teaching content relevant and purposeful. It is thus suggested that the association of these factors is investigated in future studies. Another possible area of future research would be to investigate the potential of developing a language teacher training module on best practices for learner motivation and motivational strategies. Moreover, more resources should be made available for L2 teachers so as to ensure the adoptability of this suggestion.

Several studies investigating students' perceptions of their improvement (cited in Yang \& Lau, 2003) have revealed that university students complain about the redundancy of some materials and the lack of authenticity. Many of these students argued that some of the abilities they required could have been taught on the job rather than during a whole university semester. Language teaching must hence cater to the potential careers, future aspirations and needs of the students in future situations for students to maintain motivation. Interactive teaching methods and authentic language use have been shown on numerous occasions to enhance comprehension and communicative abilities. Research has shown that interactive classes which use entertainment and student interventions made teachers more aware of the needs of the learners to understand and improve their communicative competence. In general, therefore, it seems that only when learning is communicative and meaningful can students get the motivational need to fully embrace taking part in directing the learning process. In addition, teachers as well as policy makers need to realise motivation as an ongoing process and not only a starting or an end point.

To conclude, there is no single motivational strategy that should be promoted but instead, a range of the above working together. However, such strategies discussed above will only work to full effect if students have more involvement from the beginning. This is a step that many schools are still unwilling to take. Many teachers feel that interactive classes require too much time and effort and do not always correlate to the curriculum design. Again, this is support for the idea that there needs to be more learner involvement higher up the scale in regard to setting the syllabus or curriculum. Students should not be relying on teacher-led classes anymore but on other means such 
as technology-based activities which promote autonomy and diverse learning strategies. Despite its illustrative nature, this paper offers some insight into motivation and motivating in EFL contexts. The paper concludes that there appears to be a major deficit in empirical language learning research related to motivation and the positive effects gained when students have more control within a specifically communicative-based learning environment. Large randomised controlled research trials could provide more definitive evidence for the potential of learner autonomy and use of technology in motivating EFL learners. Results of such endeavours could have several important implications for future practice.

\section{REFERENCES}

Alison, J. (1993) Not bothered? Motivating reluctant language learners in Key Stage 4. London: CILT.

Bahous, R., Bacha, N. \& Nabhani, M. (2011) Motivating students in the EFL classroom: A case study of perspectives. English Language Teaching, 4(3), 33-43.

Benson, P. (2000) Autonomy as a learners' and teachers' right. In: Sinclair, B., McGrath, I. \& Lamb, T. (eds.) Learner autonomy, teacher autonomy: Future directions. London: Longman, pp. 111-117.

Chambers, G. N. (1999) Motivating language learners. Clevedon: Multilingual Matters.

Cheng, H. \& Dörnyei, Z. (2007) The use of motivational strategies in language instruction: The case of EFL teaching in Taiwan. Innovation in Language Learning and Teaching, 1(1), 153-174.

Clément, R. (1980) Ethnicity, contact and communicative competence in a second language. In: Giles, H. M., Robinson, W. P. \& Smith, P. M. (eds.) Language: Social psychological perspectives. Oxford: Pergamon, pp. 147-154.

Covington, M. V. (1999) Caring about learning: The nature and nurturing of subject-matter appreciation. Educational Psychologist, (2), 127-136.

Dörnyei, Z. (1990) Conceptualizing motivation in foreign-language learning. Language Learning, 40(1), 45-78.

Dörnyei, Z. (1994) Motivation and motivating in the foreign language classroom. The Modern Language Journal, 78(3), 273-284.

Dörnyei, Z. (1998) Motivation in second and foreign language learning. Language teaching, 31(3), 117-135.

Dörnyei, Z. (2001) Motivation strategies in the language classroom. Cambridge: Cambridge University Press.

Dörnyei, Z. \& Csizér, K. (1998) Ten commandments for motivating language learners: Results of an empirical study. Language Teaching Research, 2(3), 203-229.

Dörnyei, Z. \& Ottó, I. (1998) Motivation in action: A process model of L2 motivation. In: Working Papers in Applied Linguistics, Thames Valley University, Vol. 4, pp. 43-69.

Dörnyei, Z. \& Skehan, P. (2003) Individual differences in second language learning. In: Doughty, C. \& Long, M. (eds.), Handbook of second language acquisition. Oxford: Blackwell, pp.589-630.
Fortini, M. \& Fitzpatrick, M. (2000) The universal design for promoting self-determination. In: Villa, R. \& Thousand, J. (eds.), Restructuring for caring and effective education: Piecing the puzzle together, ( $\left.2^{\text {nd }} \mathrm{ed}.\right)$, pp. 575-589.

Gardner, R. C. (1983) Learning another language: A true social psychological experiment. Journal of Language and Social Psychology, 2(2-3-4), 219-239.

Gardner, R. C. (1985) Social psychology and language learning: The role of attitudes and motivation. London, Ontario: Edward Arnold.

Gardner, R. C. (1996) Motivation and second language acquisition: Perspectives. Journal of the Canadian Journal of Applied Linguistics, 18(2): 19-42.

Gardner, R. C. (2000) Correlation, causation, motivation, and second language acquisition. Canadian Psychology, 41(1), 10-24.

Gardner, R. C. (2006) The Socio-Educational Model of Second Language Acquisition: A Research Paradigm. EUROSLA Yearb, 6, 237-260.

Gardner, R. C. (2014) Attitudes and motivation in second language learning. In Bilingualism, multiculturalism, and second language learning, (pp. 63-84). Psychology Press.

Gardner, R. C., Masgoret, A. M., Tennant, J. \& Mihic, L. (2004) Integrative motivation: Changes during a yearlong intermediate-level language course. Language Learning, 54(1), 1-34.

Hsu, L. (2017) EFL learners' acceptance of technology in a computer-assisted language learning (CALL) context: The role of intrinsic-extrinsic motivation in English learning. International Journal of Information and Education Technology, 7(9), 679-685.

Hull, C. L. (1943) Principles of behavior: An introduction to behavior theory. Michigan: Appleton-Century-Crofts.

Johnson, R. W., Kelly, R. J. \& LeBlanc, B. A. (1995) Motivational basis of dissonance: Aversive consequences or inconsistency. Personality and Social Psychology Bulletin, 21(8), 850-855.

Leis, A., Tohei, A. \& Cooke, S. (2018) Smartphone assisted language learning and autonomy. In: Handbook of Research on Integrating Technology into Contemporary Language Learning and Teaching. IGI Global, pp. 307-327.

Little, D. (1991) Learner autonomy: Definitions, issues and problems. Italy: Authentik Language Learning Resources.

Liuoliene, A. \& Metiuniene, R. (2006) Second language learning motivation. Santalka. Filologija. Edukologija, 14(2), 93-98.

MacIntyre, P. D. (1999) Language anxiety: A review of the research for language teachers. Affect in foreign language and second language learning: A practical guide to creating a low-anxiety classroom atmosphere. Boston: McGraw-Hill, pp. 24- 45.

MacIntyre, P. D. \& Vincze, L. (2017) Positive and negative emotions in motivation for second language learning. Studies in Second Language Learning and Teaching. 4(2), 237-274.

McNinch, G. W. (1997) Earning by learning: Changing attitudes and habits in reading. Reading Horizons, 37(3), 186-194. 
Oldfather, P. (1995) Commentary: What's needed to maintain and extend motivation for literacy in the middle grades. Journal of Reading, 38(6), 420-422.

Oxford, R. L. (ed.) (1996) Language learning strategies around the world: Cross-cultural perspectives. Honolulu, HI: University of Hawai'i Press.

Oxford, R. L. \& Amerstorfer, C. M. (eds.), (2018) Language learning strategies and individual learner characteristics: Situating strategy use in diverse contexts. Bloomsbury Publishing.

Rogers, C. R. (1961) On becoming a person: A therapist's view of psychotherapy. London: Constable.

Rose, D. H., Meyer, A., Strangman, N. \& Rappolt, G. (2002) Teaching every student in the digital age: Universal design for learning. Alexandria, VA: Association for Supervision and Curriculum Development.

Ryan, R. M. \& Deci, E. L. (2000) Intrinsic and extrinsic motivations: Classic definitions and new directions. Contemporary Educational Psychology, 25, (1), 54-67.

Ryan, R. M., \& Stiller, J. (1991) The social contexts of internalization: Parent and teacher influences on autonomy, motivation and learning. In Pintrich, P. R. \& Maehr, M. L. (Eds.), Advances in motivation and achievement: Vol. 7, Goals and self-regulatory processes. Greenwich, CT: JAI, (pp. 115-149).

Saito, K., Dewaele, J. M. \& Hanzawa, K. (2017) A longitudinal investigation of the relationship between motivation and late second language speech learning in classroom settings. Language and Speech, 60(4), 614-632.

Schunk, D. H. (1983) Ability versus effort attributional feedback: Differential effects on self-efficacy and achievement. Journal of Educational Psychology, 75(6), 848-856.

Shih, Y. C. \& Reynolds, B. L. (2018) The effects of integrating goal setting and reading strategy instruction on English reading proficiency and learning motivation: A quasi-experimental study. Applied Linguistics Review, 9(1), 35-62.

Spada, N. \& Lightbown, P. M. (1993) Instruction and the development of questions in L2 classrooms. Studies in second language acquisition, 15(2), 205-224.
Terrell, S. \& Rendulic, P. (1996) Using computer-managed instructional software to increase motivation and achievement in elementary school children. Journal of Research on Computing in Education, 28(3), 403-414.

Thanasoulas, D. (2002) Motivation and motivating in the foreign language classroom. [Online] Available at: www. http//itesjl.org//Articles//Thanasoulas -Motivation.html (Accessed: 11 February 2018).

Ushioda, E. (1997) The role of motivational thinking in autonomous language learning. In: Little, D. \& Voss, B., (eds.) Language centres: Planning for the new millennium. Plymouth, England: CERCLES, pp. 38-50.

Ushioda, E. (2014) Motivation, autonomy and metacognition: Exploring their interactions. In: Lasagabaster, D., Doiz, A. and Sierra, J.M., (eds.) Motivation and Foreign Language Learning: From Theory to Practice. Language Learning \& Language Teaching (Volume 40). Amsterdam: John Benjamins, pp. 31-49.

White, R. W. (1959) Motivation reconsidered: The concept of competence. Psychological Review, 66, (5), 297-333.

Williams, M. (1994) Motivation in foreign and second language learning: An interactive perspective. Educational and child psychology, 11(2): 77-84.

Wlodwoski, R. J. (1985) Enhancing adult motivation to learn. San Francisco: Jossey-Bass.

Woodrow, L. (2017) Motivation in language learning. In: Breeze, R. \& Sancho-Guinda, C. (eds.), Essential competencies for English-medium university teaching, Switzerland: Springer, pp. 235-248.

Zhou, H. (2012) Enhancing non-English majors' EFL motivation through cooperative learning. Procedia Environmental Sciences, 12(2012): 1317-1323.

Zhou, Q. (2018) The Challenges Facing EFL Motivation in China and the Discussion of Possible Solutions. DEStech Transactions on Economics, Business and Management, $3^{\text {rd }}$ International Conference on Society Science and Economics Development (ICSSED). 